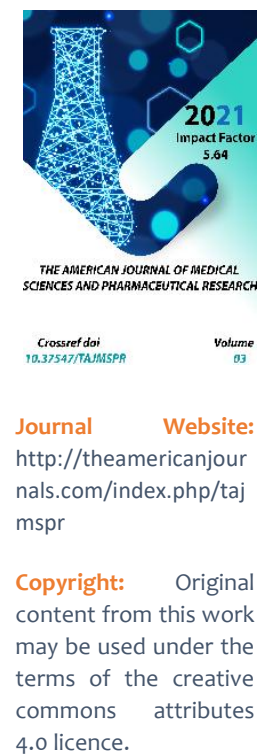

\section{Osteosynthesis With Elastic Titanium Nail For Fractures Of Long Bones Of The Lower Extremities In Children}

\author{
Shomatov Khasan Shavkatovich \\ SI Republican Specialized Scientific And Practical Medical Center Of Traumatology And \\ Orthopedics, Tashkent, Uzbekistan \\ Khodjanov Iskandar Yunusovich \\ SI Republican Specialized Scientific And Practical Medical Center Of Traumatology And \\ Orthopedics, Tashkent, Uzbekistan \\ Lutpillaev Azamjon Khabibullo Ugli \\ SI Republican Specialized Scientific And Practical Medical Center Of Traumatology And \\ Orthopedics, Tashkent, Uzbekistan
}

\title{
ABSTRACT
}

In recent years, approaches have been used to treat diaphyseal fractures in children and adolescents, which make it possible to shorten immobilization and hospitalization time as soon as possible, as well as return to normal life as soon as possible. In a retrospective study, the conservative treatment of diaphyseal hip fractures was compared with the closed elastic method of rod fixation. In the period from 2014 to 2019. In our clinic, 11 diaphyseal fractures of the femur and 16 tibia were treated. In all cases, elastic rod osteosynthesis was used. Conservative treatment gave more complications (difference in limb length and inaccurate reduction). In case of the closed fracture fixation with the help of flexible rods the consolidation and fast mobilization with small number of complications was achieved.

\section{KEYWORDS}

Osteosynthesis, elastic rods, diaphyseal femur fractures, children.

\section{INTRODUCTION}

In the clinic of pediatric traumatology, Research Institute of TO for 2014 to 2019. treated 27 children with fractures of the long bones of the lower extremities; of the femur 11, fractures of the tibial bones - 16. Among them are diaphyseal fractures of the femur in 6 , and of the tibial bones in 12 children.

Metadiaphyseal fractures of the femur were observed in 5 and lower limb bones in 4 
children. The number of boys with fractures of the femur was 8 , the bones of the lower limb 10 , girls, respectively, 3 and 6 . The age of patients from 5-7 years $-7,8-10$ years $-11,11-16$ years -7 . Right-sided injuries prevailed, accounting for 18 children.

All patients underwent standard X-ray examinations. In 5 children with metadiaphyseal fractures of the femur, multispiral computed tomography was performed to check for intact metaphyses. In all diaphyseal fractures, osteosynthesis was performed under IIC(Image Intensifier Control). When selecting the elastic rod, the standard was adhered to that the construction filled $40 \%$ of the medullary canal diameter. To create a stable elastic position, the arcuate bends of the rods must intersect in the fracture area and be located opposite to each other.

For osteosynthesis, a standard adapted set of surgical instruments was used. In fractures of the middle third, the rods were inserted retrograde, and in metadiaphyseal fractures, elastic rods were inserted antegrade. All digital materials have been statistically processed.

RESULTS AND THEIR DISCUSSION
Indications for this type of osteosynthesis are unstable oblique or comminuted diaphyseal and metadiaphyseal fractures of the femur and lower limb bones, transverse diaphyseal fractures with displacement and fractures with interposition of soft tissues.

Contraindications to this type of osteosynthesis are: helical or spiral fractures with a long fracture line, double fractures, active bone infections or infectious processes in the area of rod insertion.

In the preoperative period, patients were examined according to diagnostic standards for the volume of surgical interventions: general clinical analyzes, standard X-ray examinations, multispiral computer tomography. In the postoperative period, general clinical studies were checked in dynamics in the monitoring mode. The radiographic method was used to verify the degree of reduction of bone fragments, the position of metal structures in the bone marrow canal, and the degree of fusion.

The results were studied in all patients in the period of fusion up to three years.

The results were evaluated on a three-point scale.

\begin{tabular}{|c|c|c|c|}
\hline Results & Good & Satisfactory. & Unsatisfactory \\
\hline Femur & 8 & 3 & - \\
\hline Tibial bones & 9 & 3 & - \\
\hline
\end{tabular}

The advantage of this technique is that it is minimally invasive among the existing techniques, in addition to the above, the method has a low level of purulent complications. The absence of additional immobilization and restoration of support ability after 2-3 months gives the child an early return to a full life. The reposition of bone fragments under the image intensifier and the introduction of elastic pins through small incisions determine the priority of this 
osteosynthesis in childhood. In case of multisplinter fractures, with pathological fractures and in patients with polytrauma in urgent conditions, it is advisable to use a lowtraumatic intervention. The absence of surgical aggression in the area of the fracture creates favorable prerequisites for the consolidation of the damaged bone. Sufficient stability of bone fragments excludes the use of additional external immobilization with a plaster cast or different splints. The child, starting from the first month of osteosynthesis, is allowed to load the injured limb and this mechanically stimulates the consolidation of the fracture.

Here is a clinical example. B-th. U.13 p. He was injured as a result of an accident, the diagnosis was "multi-fragment fracture of the lower metadiaphysis of the right femur with displacement of bone fragments" (Fig. 1a). On the third day the patient was fixed with stable elastic osteosynthesis with titanium rods(pic 16). Reposition under the $C$-arm, the operation was carried out as usual. Duration of inpatient treatment is 8 days. The patient began to walk a month after the osteosynthesis. In dynamics, a control X-ray was observed, where complete consolidation of bone fragments was determined in a period of one year, and after which the rods were removed without any special technical difficulties(pic 1B). In this case, no additional external traction devices were used during the reduction of bone fragments. In the presence of sufficient stable elasticity, a comminuted fracture of the femur was well consolidated within a year. We did not observe a shortening of the hip in this case. The function of knee was full.

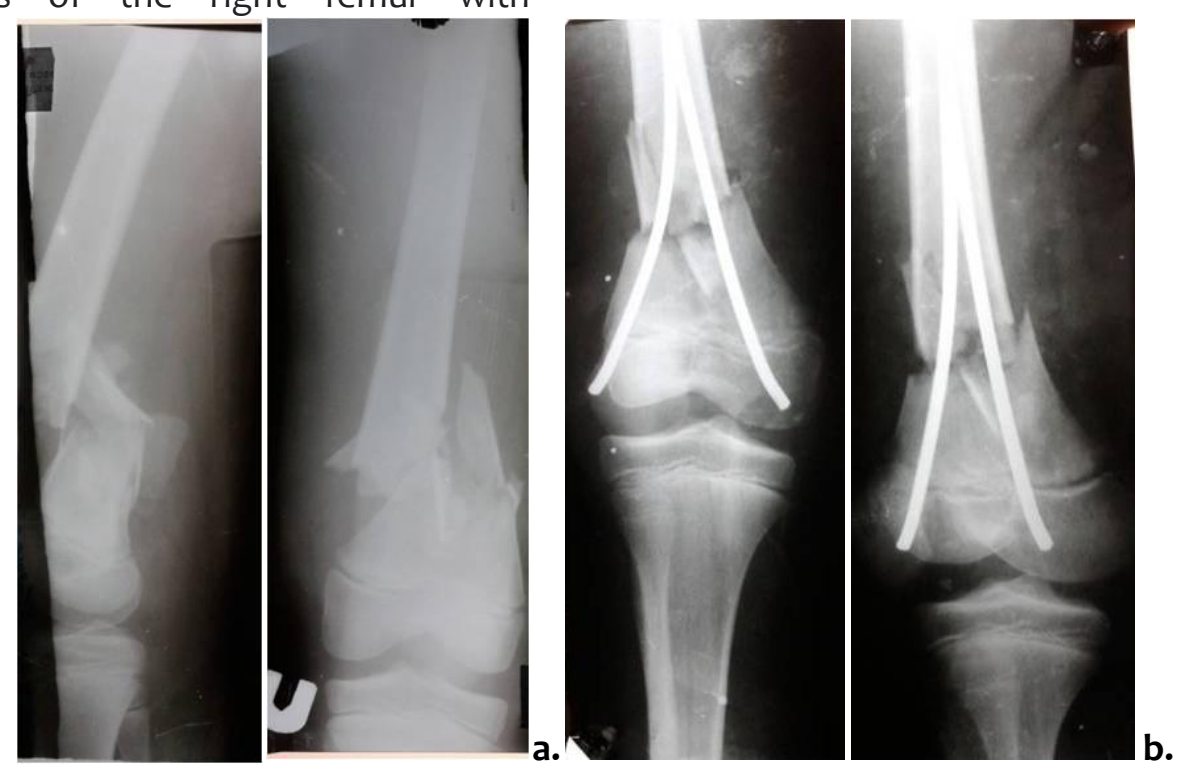




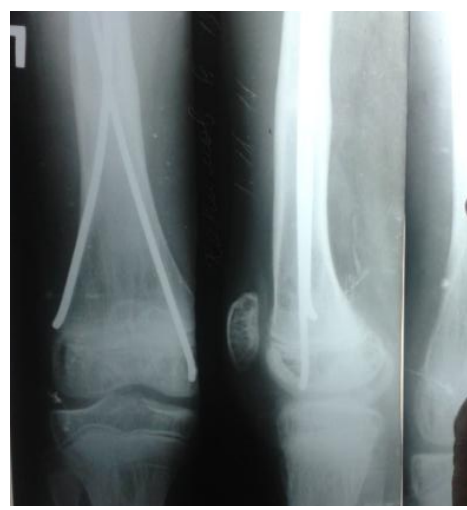

c.

Fig. 1. B-th. A. 13 p. Diagnosis: "Closed multifragmented fracture of the distal metadiaphysis with displacement of bone fragments (a), condition after osteosynthesis (b), result after a year (c).

Like all other types of osteosynthesis, this type also has its own characteristics when carrying out osteosynthesis of the bones of the lower extremities. In diaphyseal fractures of the femur, closed reduction of bone fragments without traction devices creates certain technical difficulties in juxtaposing the fragments, due to the massive muscles of the femur, but the rods are carried out without any special technical difficulties.

In case of distal fractures, the reposition of bone fragments is carried out without technical difficulties, but the placement of the rods creates some technical difficulties, because The metaphyseal part of the child's bone is very soft and requires caution when performing osteosynthesis.

To prevent this factor, a bony canal is created in the femoral epiphysis at an angle of $45^{\circ}$ relative to the long axis of the femur. Then a $40-45^{\circ}$ bend is made at the inserted end of the post and the rod is passed into the bone marrow canal. In all cases, the bends of the pins should be opposite each other and should intersect close to the fracture line to create an elastic tensive condition.

The elastic tensive condition, which is also present in other types of osteosynthesis, actively stimulates the bone reparative process in the fracture area, which was proved by the scientists of the school of G.A. Ilizarov.

This technique has proven itself in case of fractures of the shin bones. Clinical example. Patient. K. 14 p. I was injured while training "parkour". In the preoperative period, a skeletal traction system was applied (Fig. 2 a). Then, according to the above indications, osteosynthesis with elastic rods was performed. Under intravenous anesthesia, bone fragments were repositioned and stably elastic osteosynthesis with rods (Fig. 2b).

Duration of inpatient treatment is 8 days. The patient began advancing limbs 3 weeks after osteosynthesis. I contacted a year later. On the control X-ray there is complete consolidation of bone fragments and then elastic rods were removed (Figure $2 \mathrm{C}$ ). 

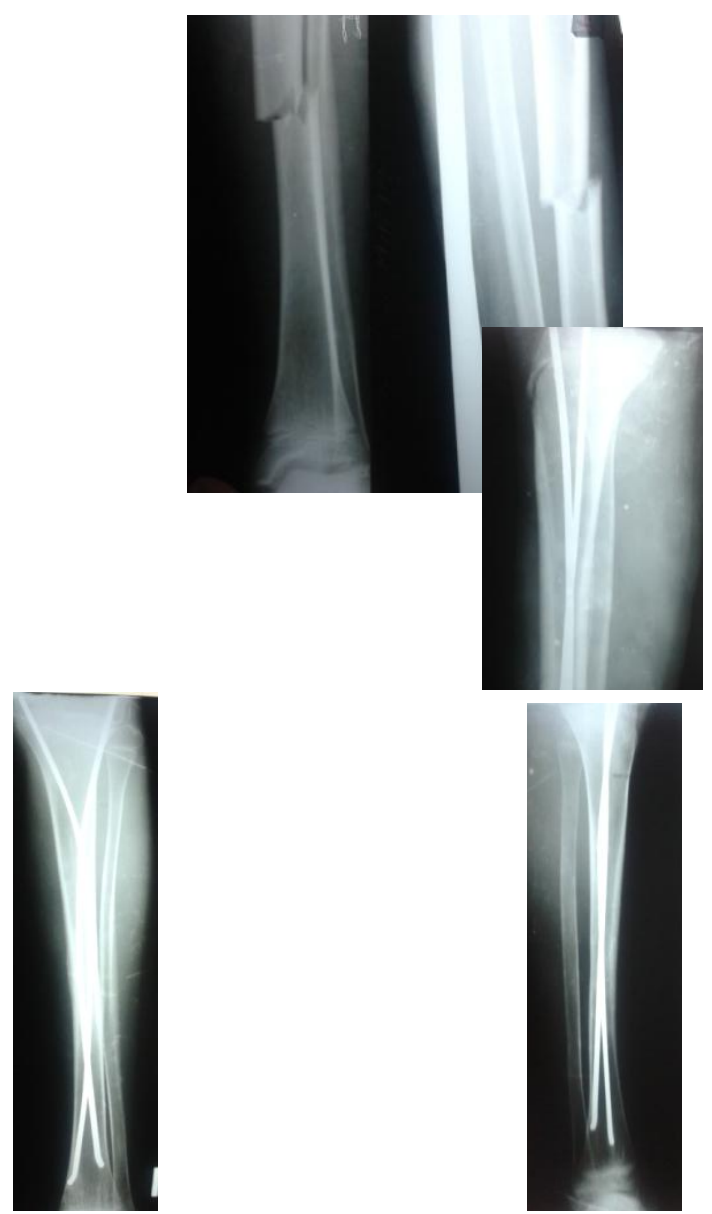

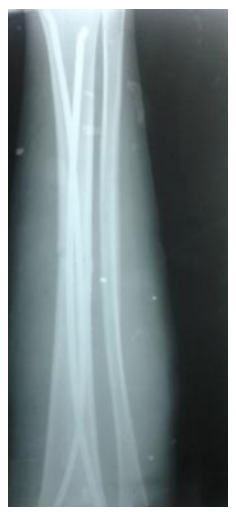

b.

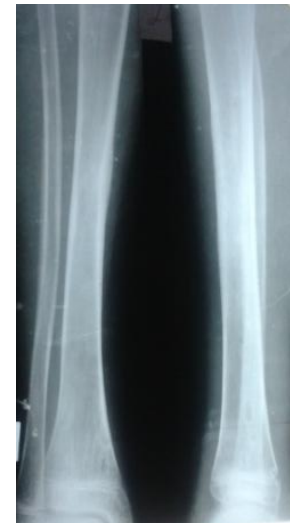

Fig 2. B-th. K. 14 p. "Closed fracture of the middle third of the bones of the right lower leg with displacement of bone fragments" (a). Condition after osteosynthesis (b). Long-term result in a year and after removal (c).

Thus, fractures of the long bones of the lower extremities, due to the peculiarity of the characteristics and consolidation of bone fragments, create certain difficulties in treatment and rehabilitation. Skeletal traction is a more physiological treatment for fractures of the lower extremities, but the duration of involuntary immobilization is not always acceptable for children.

In the arsenal of pediatric traumatologists, there are several types of minimally invasive methods of osteosynthesis. Among these methods of surgical treatment, in our opinion, we consider stable-elastic osteosynthesis with titanium rods to be acceptable. The advantages of this type of osteosynthesis are its low trauma, short duration of inpatient treatment and the possibility of early activation of patients.

Those difficulties in carrying out osteosynthesis with elastic rods are also present in other types of osteosynthesis, without overcoming them, of course, it is not possible to stabilize the fragments. It is especially important to carry out osteosynthesis and create stability of fragments in unstable conditions, where sometimes additional rods or additional external immobilization are required, which 
does not at all implore the merit of any method.

When carrying out elastic osteosynthesis, we believe that dynamic X-ray control is needed to determine the value of the elastic state, because sometimes elastic tension, especially when the patient starts walking, diastasizes bone fragments, which requires a change in the length of the rods, changing their point of contact. Of course, this significantly reduces the rigidity of the bone-fixator system, sometimes requiring additional fixation.

With all its excellent qualities, elastic rod osteosynthesis should not be opposed to other low-traumatic types of osteosynthesis, especially external spoke-rod osteosynthesis, which also has a significant advantage over traditional types of osteosynthesis. In the requirements of osteosynthesis for adults, there is a factor of the comfort of the osteosynthesis for the patient. And we think that this factor should be carried over for children as well. In this context, elastic intramedullary osteosynthesis, in addition to its above-mentioned qualities, has an indisputable superiority.

An important factor in the healing of fractures is the restoration of the function of nearby joints. At the same time, the above other methods of fixation are not inferior to each other, since in both types of osteosynthesis, the joints are not immobilized or fixed for a short time, which ultimately creates conditions for early restoration of joint function. With external immobilization of bone fragments with external rod systems, the work of the joints has some limitations due to the fixation of muscle sheaths, sometimes creating inflammatory processes around the rods. This requires a long treatment or replacement. Elastic intramedullary nail osteosynthesis also has such costs, but the function of the joints is not affected.

The rods should be guided in such a way that they should not enter over the bone and also should not be deeply guided, which leads to a decrease in the strength of the stress state and creates technical difficulties in removing them. Therefore, elastic intramedullary rod osteosynthesis is also a dynamic system, which requires constant medical supervision at all stages of fusion.

\section{CONCLUSION}

Thus, osteosynthesis of pediatric diaphyseal fractures requires careful selection of indications for surgical treatment and selection of the type of osteosynthesis, which should correspond to the anatomical and functional state of the growing organism. The low trauma of the operation, the preservation of the function of the joints and the comfort of wearing metal clamps are especially important attributes of fixing bone fragments in children.

In this context, intramedullary osteosynthesis with elastic rods is superior to the currently existing methods of fixing diaphyseal fractures of the lower extremities. Our results show that the method can be widely applied in various pediatric clinics.

\section{REFERENCES}

1. Немсадзе В.П., Выборное Д Ю,, Тарасов Н.И., Лященко О.А., Мелъцин И.И. «Металлостеосинтез при переломах бедренной кости у детей».// Сборник материалов XI педиатров России . Москва 2007г. - С. 482-483.

2. Ю.Е. Первунинская, Д.А. Попков «Наш опыт применения интрамедуллярного 
эластичного стабильного остеосинтеза при лечении диафизарных переломов бедра у детей» Гений Ортопедии № 1, 2013 г.24.

3. Мельцин И.И. «Дифференцированный металлоостеосинтез при диафизарных переломах длинных трубчатых костей нижних конечности.// Автореферат на соис.уч.степ.канд.мед.наук. Москва 2009. - c.24.

4. Ho C.A., Skaggs D.L., Tang C.W., Kay R.M. Use of the flexible intramedullary nails in pediatric femur fractures. $J$ PediatrOrthop. 2006 Jul-Aug;26(4):497504.

5. Elastic stable intramedullary nailing of femoral shaft fractures in children /J.N. Ligier, J.P. Metaizeau, J. Prévot et al. //J. Bone Joint Surg. - 1998. - V. 70. - P. 7477.

6. Interlocking intramedullary nailing of femoral-shaft fractures in adolescents: preliminary results and complications /J.H. Beaty, S.W. Austin, W.S. Warner et al. //J. Pediat. Orthop. - 1994. - V. 14. - P. 178-183.

7. Bar-On, E. External fixation or flexible intramedullary Nailing for femoral shaft fractures in children /E. Bar-On, S. Sagiv , S.Porat //J. Bone Joint Surg. - 1997. - V. 79. - P. 975-978.

8. Buford, D. Intramedullary nailing of femoral fractures in adolescents /D. Buford, R. Christensen, P. Weatherall //Clin.Orthop. - 1998. - N b350. - P. 85-89.

9. L'ostéosynthesé stable élastigue,nouveau concept biomécanigue: etude expérimentale /A. Firica, R.Popescu, M. Scarlet et al. //Rev. Chir. Jrthop. - 1981. N 67 II. - P. 82-91.

10. Titanium elastic nails for pediatric femur fractures: a multicenter study of early results with analysis of complications /J.M. Flynn, T. Hresko, R.A. Reynolds et al. //J. Pediatr Orthop. - 2001. - N 21. - P. 4-8. 